\title{
AS NEO-VANGUARDAS E A CIDADE
}

Prof. Dr. Fábio Lopes de Souza Santos ${ }^{1}$

\section{Resumo}

A produção contemporânea em arte e arquitetura se constrói a partir dos frutos da efervescência dos anos 60, embora esta conexão possa soar estranha a primeira vista: a nossos olhos o horizonte utópico da neo-vanguarda parece pertencer a outra era geológica. Paradoxalmente, enxergamos com maior clareza a continuidade entre as formas artísticas empregadas hoje e aquelas geradas pela neovanguarda do que a dinâmica de fundo que as impulsionou e transformou substancialmente. Paulatinamente, passou-se, nas últimas quatro décadas do discurso moderno contra o caos urbano para outro, que elogia sua heterotopia, tendo como elo justamente manifestações neovanguardistas. Houve um deslizamento gradual desde a hegemonia moderna até a atual apologia da "pluralidade". A presente comunicação passa em revista algumas produções da neovanguarda artística e arquitetônica, procurando discernir por detrás de sua exorbitante diversidade algumas motivações compartidas subjacentes para, num segundo momento, procurar entender a natureza desta paradoxal transformação.

\section{Neo-vanguardas e a Cidade.}

A produção contemporânea em arte e arquitetura se constrói a partir da efervescência dos anos 60, embora esta conexão possa a primeira vista soar estranha: a nossos olhos o horizonte utópico da neo-vanguarda parece pertencer a outra era geológica. A presente comunicação passa em revista produções da neovanguarda artística e arquitetônica, procurando discernir por trás da exorbitante diversidade algumas motivações subjacentes para, num segundo momento, procurar entender esta paradoxal transformação.

\section{Rauschenberg, Cage e Kaprow: emergência de uma nova sensibilidade.}

"Monograma" é, sem dúvida, uma das obras contemporâneas mais conhecidas. Encontramos em toda parte sua enigmática imagem de cabrito montanhês com face multicolorida que entre pelos sedosos e compridos, ostenta um prosaico pneu. Não menos inusitada é a sua base, mescla de baixo relevo e colagem com toques de tinta e cuja horizontalidade dificulta a visualização. Podemos imaginar as dificuldades enfrentadas por um observador educado nos paradigmas modernistas ao interpretar esta obra. Possivelmente tropeçaria ao tentar conceder algum sentido ao pneu em volta do animal, à pintura em sua face, ou algum nexo aos seus inusitados elementos. Se observasse outras obras de Robert Rauschenberg, estranhamento semelhante acompanharia sua percepção; seu olhar ao percorrer a extensão do quadro encontraria dificuldade em unir as imagens esparzidas em um agrupamento sintético, que resistem a se aglutinar em subgrupos visuais. Rauschenberg abdica do papel de ordenador ou de intérprete. A fragmentação cubista ainda configurava uma hierarquia que remetia a uma totalidade. Já a estratégia de Rauschenberg ao lidar com fragmentos é outra: a ausência de hierarquia em suas "composições" materializa uma mudança radical de sensibilidade. Seu trabalho se dirige a um sujeito que aceita o fluxo de imagens

\footnotetext{
${ }^{1}$ Departamento de Arquitetura e Urbanismo. Escola de Engenharia de São Carlos. Universidade de São Paulo.
} 
díspares e abandona o esforço de integra-las em uma totalidade. Os procedimentos utilizados pelo artista são familiares ao modernismo, mas não sua sintaxe e semântica: o significado das imagens permanece estranhamente neutro. A gestualidade se apresenta mecânica, a enorme escala da tela fragmentada e o inacabado da composição esteticizado. Imagens e procedimentos comparecem na obra, mas sem fazer referência a algum valor além da própria presença, perdendo intencionalidade e impulso expressivo. Paradoxalmente, é este vácuo, a suspensão de significado definido, que seduz. O observador também pode indagar pelo artista, o sujeito responsável pela sensibilidade organizadora. Qual foi a intenção que norteou a escolha destes materiais: está criticando, sendo irônico ou apologético? Estes interrogantes suscitam outros: se ele não propõe nem utopia nem apologia, devemos, portanto, estar perante um universo pessoal. Mas tudo que antes indicava gesto ou visão pessoal foi obliterado, toda destreza do ofício foi deixada de lado em favor de operações como decalcar, pincelar, colar ou pregar. É claro que a estruturação dos elementos é sofisticada, mas é a simplicidade e imediatez do gesto que ganham a simpatia do observador, que sente poder fazer algo semelhante. Paradoxalmente, um dos cavalos de batalha da vanguarda aparece magicamente realizado: a síntese entre arte e vida, aliás como o próprio artista declarava: "Trabalbo na defasagem entre a Arte e a Vida". Suas assemblages são resultado do gesto que recolhe detritos heterogêneos, disparando cadeias de associações, deixando-as em aberto para o público dota-las de significado.

A obra de Rauschenberg encaixa-se sem dificuldade dentro do conjunto de manifestações que emergiu ao final dos anos 50. Nelas encontramos um forte impulso iconoclasta como condição para experiências novas, traduzido na época por Susan Sontag: "devemos aprender a ver mais, a ouvir mais, a sentir mais". No Black Mountain College, Rauschenberg fora aluno de Jonh Cage. Essencial para Cage foi a inclusão de sons "não-musicais": "enquanto que no passado o ponto de discórdia era entre a dissonância e a consonância no futuro próximo ele será entre o ruido e os assim chamados sons musicais". Sua "música" incluía elementos absolutamente exteriores à tradição: o concerto "4’33" de 1952 consistia na audição dos cinco minutos de silêncio de um intérprete parado frente ao piano- situação cujo estranhamento devolvia ao público a consciência de si mesmo em uma sala de audição. Convertida em "collage de situações", sua música converteu-se em estratagema para vencer a "defasagem entre arte e vida". Ao invés de "representar", ela prefere "apresentar" ou ainda deixar evidente a situação concreta da comunicação artística, o local, a própria presença, tudo que constitui o ritual da audição. Nesta linha, outro passo decisivo foi dado por Allan Kaprow, também aluno de Cage, quando passou a organizar bappenings incorporando não apenas aleatoriamente elementos materiais do cotidiano, mas também ao utilizar o próprio espaço urbano como suporte. Devemos ir além da esfera da arte para imaginar a razão destas experimentações que apontam a maturidade de uma nova percepção. Na música de Cage o elemento aleatório contrapõe-se à racionalidade da forma, encarnando a esperança de que uma percepção mais ampla ultrapassasse a "percepção programada", mostrando ao público uma maneira inusitada de se apropriar do cotidiano. É justamente a aparente desordem (a confluência e colisão de ordens heterogêneas) reinante nestas obras que deve reeducar a associação perceptiva do observador. Tais obras pretendem ajudar a criar uma sensibilidade aberta à heterotopia da vida contemporânea: as imagens que nos assaltam quotidianamente devem ser desfrutadas como uma sucessão de estruturas sensíveis. Kaprow, como Rauschenberg ou Cage, defendiam o apagamento das fronteiras entre obra e cotidiano como um procedimento que visava criar uma nova harmonia entre sujeito e 
objeto, promovendo a plena aceitação da aleatoriedade presente na sociedade capitalista industrial.

\section{Diversidade de propostas}

Numa clara recusa ao alto modernismo vigente, ambientes, happenings e performances sedimentaram-se como formas de experimentação nas quais era característica a atitude de "inclusão", propícia ao inesperado ou mesmo à transgressão. Levantando-se contra o comportamento induzido, contra a cidade funcional, estas manifestações estéticas reivindicavam uma nova articulação entre vida, estrutura urbana e produção. Abrangendo desde novas atitudes na vida quotidiana até novas propostas de politização, estas manifestações, em seu estonteante experimentalismo, não esqueceram a invenção de rituais urbanos ou a revalorização do misticismo. Esta atitude define o trabalho de Fluxus. Segundo Robert Watts "a coisa mais importante sobre o Fluxus é que ninguém sabe o que ele ê". Singularmente, o grupo originou-se nos festivais de música de Darmstadt, ampliando depois suas atividades para outras artes. A declaração de Wolff Vostell, "todo processo vital pode ser sentido como um processo artístico", define os objetivos do Fluxus. Encarando o estético como emancipação, arquitetaram suas obras visando ampliar a participação do público. Sua produção enfocou os acontecimentos "cotidianos": surgiram assim casamentos ou comidas fluxus que hibridizavam de maneira inextricável "vida" e arte. Sua temática estendeu-se ao urbano, encarado como um sistema de fluxos de atividades e informações. Suas táticas opunham-se à mercantilização e à autonomia da arte; almejavam "ressemantizar" o cotidiano. Não se tratava de "representar" o cotidiano, mas de operar nele por meio de intervenções que atuando como ruído, interromperiam o fluxo da vida programada. Paradigmático foi o happening de Vostell, "Im Ulm, um Ulm, um Ulm herum", de 1964, no qual mães com máscaras de gás e carrinhos de bebê passearam dentro do subterrâneo de uma garagem. Também a atuação da Internacional Situacionista materializou a recíproca influência entre reflexão e arte, constituindo uma ponte com a política no sentido forte do termo ao pautar-se pela "resistência a um urbanismo disciplinador e inibidor dos desejos". Os situacionistas queriam ampliar as fronteiras da arquitetura, de maneira a permitir que a vivência urbana voltasse a ser totalizadora e aberta a todas as possibilidades existenciais. Enfatizando as relações entre espaço e comportamento, eles concebiam o habitat como um "cenário para totalidade da vida" e a cidade como "usina do imaginário social". As propostas situacionistas materializavam-se na invenção e na prática de "jogos”, criação coletiva entendida como "alternativa revolucionária a uma vida planificada", encarada como meio de expandir a percepção dos participantes de si, entre si e do ambiente. Uma proposta sua consistia em colocar uma pequena multidão em marcha, cujo percurso por alguns quilômetros da cidade formava uma linha absolutamente reta e independente da configuração do tecido urbano. Esta defasagem dava lugar a práticas inusitadas: rasgando literalmente o tecido urbano, a multidão marcharia sobre automóveis, penetraria em espaços privados, em suma, invadiria e atrapalharia a marcha do cotidiano. $\mathrm{Na}$ "deriva contínua", o espaço urbano converter-se-ia em palco de perambulações coletivas, realizadas como tática de estranhamento para recuperar o sentido da experiência urbana, que os situacionistas acreditavam ameaçado pela "sociedade do espetáculo". Atingiu-se nesta época, por meio deste arco de diferentes manifestações, outra compreensão da natureza do espaço urbano contemporâneo, que deixou de ser entendido como apenas o espaço onde acontece a produção ou se inserem "objetos de arte" e passou a ser concebido 
como o suporte de um fluxo de diferentes redes de sociabilidade: empregando estes canais, a intervenção artística ganharia outra ressonância. Os happenings provocaram a ordem pública para estender os limites da "normalidade", politizaram o "comportamento". Levantando-se contra a estética alto-modernista esbarraram, ao final, no sistema fordista de produção, homogeneizador de vivências e nas limitações do Estado de Bem-Estar Social. Coroando estes esforços, estudantes (com a ajuda de políticos e policiais) promoveram um imenso happening, ao final dos anos 60, oportunidade concedida pela conjuntura excepcional. Diversos acontecimentos cimentaram a troca entre arte, teoria e participação popular, tingindo as manifestações com o matiz de festa urbana, como bem traduz a colocação inusitada de um piano de cauda no pátio da "Sorbonne libertada", em maio de 68. "A imaginação no poder", "Sob os paralelepipedos a praia”: estes slogans evidenciavam a identificação entre emancipação política e estética. A percepção do acomodamento da classe operária, acompanhada pela crescente inquietação entre as "minorias", concedeu um novo caráter às rebeliões, que passaram a reivindicar direitos políticos e expressão de comportamentos "alternativos". A forma estética inclusiva permitiu a expressão de um amplo arco de reivindicações, justapondo questões referentes à juventude, às minorias étnicas, às mulheres e aos homossexuais. Identificando a opção política e existencial, o corpo converteu-se em suporte para a exibição de opções oposicionistas. Os "Bed-Ins" de Ioko e Lennon, exemplificam estas inovações, uma vez que combinam arte e política, neo-vanguarda (Ioko participara do Fluxus) e música pop, ativismo político e liberação de costumes, festa e espetáculo, estabelecendo uma simbiose inusitada entre performance, mídia e rebeldia política. As contrastantes proposições dos grupos neovanguardistas guardavam em comum questionar a "vivência" contemporânea, considerada restritiva. Elas retomaram questões da vanguarda heróica negativa, mas diferenciando-se destas na medida em que, o sentido profundo de suas manifestações era a ação sobre as potencialidades adormecidas da vida urbana contemporânea; nelas o cotidiano converte-se em tema e "matéria-prima", não para ser representado, mas como campo para a ação.

\section{A produção arquitetônica e a cidade.}

Naqueles anos 60, as neo-vanguardas arquitetônicas também realizaram experimentos que cumpriam o programa de apagar fronteiras. O elogio à diversidade e o interesse pelo "aqui-agora" não se restringiu em absoluto às artes plásticas. Testemunhamos nestes anos o tema "cidade" atrair a atenção crítica dentro e fora da cena cultural, convertendo-se em objeto de imensos e contraditórios desejos, que não raro bordejaram o elemento utópico. Emerge o interesse pelo "urbano" como locus onde acontecem as atividades cotidianas. Por volta dos anos 50, surgiu um discurso que valorizava o urbano como fenômeno constituído pela diversidade espacial, temporal, social e existencial. Não tardaram a emergir propostas arquitetônicas para estas demandas. Foi o arco de propostas aglutinadas em torno ao "contextualismo" que se revelou mais fértil. Estas podem ser caracterizadas por sua atitude de extremo cuidado com o entorno existente, visando sua apropriação pela população, respeitando suas peculiaridades e mesmo sua alteridade cultural. Entre os arquitetos, começouse a falar em contextualismo ao materializar-se uma profunda reestruturação do espaço, não apenas o urbano, após a Segunda Guerra Mundial. Esta reestruturação engendrou um sentimento de perda, fazendo nascer o desejo do resgate de tipos de vida urbana reprimidos ou destruídos pela Modernidade. Constatou-se que a atuação do Movimento Moderno (e 
especialmente sua diluição comercial) constituíra um fator adicional de entropia. Como reação, a neovanguarda incorporou inúmeras (e muitas vezes conflitantes) qualidades que haviam sido excluídas pelo projeto moderno, configurando uma verdadeira "inflexão" nos objetivos e metodologias deste. O repertório moderno foi questionado a partir do novo papel que a arquitetura deveria exercer. Para os defensores da nova postura era claro que o funcionalismo descuidara da cidade enquanto "obra", ao submete-la aos ditames da produção material. Em reação ao caráter abstrato do planejamento, foi ampliada a concepção da cidade. A estrutura urbana passou a ser pensada como o contexto material e simbólico que possibilita a existência de complexas teias de relações sociais. Abandonada a convicção moderna na ruptura com o existente como método único e inevitável, pensamento e prática arquitetônicos voltaram-se, em busca de saídas, para pesquisa da continuidade histórica e das possibilidades latentes do entorno. Emergiu uma consciência que preferia reciclar áreas degradadas e projetar a partir da cidade existente, adaptando-as a novas demandas. Valorizou-se a importância simbólica do tecido construído, "fruto do labor coletivo", pregando-se o respeito à sedimentação de tempos diferentes como tática para reatar e rejuvenescer os vínculos com o lugar. Redescobriu-se o conceito de "lugar", sitio presidido por um genius loci, em contraposição ao "espaço", entidade abstrata e genérica dos modernos. Assim, procedimentos que realçavam as qualidades do 'lugar' alicerçaram o centro da produção arquitetônica renovadora, no mais das vezes como resistência à modernização tecnocrática. Como Otilia Arantes sintetizou, seu objetivo era "recriar algo como uma res cívica - reatar com formas de vida social desativada, reanimar uma vida pública"2. Em certos casos este urbanismo assumiu abertamente o caráter de "revanche contra o projeto urbano moderno". Definiu-se um urbanismo alternativo que se configurou como "tático" (contraposto ao pensamento totalizador moderno), cujo método definia áreas propícias para uma série de "intervenções pontuais" que como "metástases benignas" (Bohigas) irradiariam uma influência sadia sobre o tecido urbano adjacente; concepção que reflete o interesse pelas potencialidades da "processualidade". A cidade era concebida como associada às vivências da "comunidade" local; o repertório arquitetônico, portanto, deveria refletir e reforçar os valores da comunidade acumulados ao longo do tempo. Porém, no leque de críticas à uniformização "fordista" da sociedade, nem todas as propostas arquitetônicas voltaram-se ao resgate da memória; também emergiram enfoques que centraram seus esforços no processo de produção e de apropriação, semelhantes, neste ponto, à produção artística envolta com a processualidade e a recepção aberta. Os arquitetos "estruturalistas" Hertzberger e Aldo van Eick destacaram-se ao renovar a concepção moderna de programa. Hertzberger radicalizou sua crítica ao funcionalismo, propondo a apropriação ativa do projeto pelos usuários. Seguindo o conceito que chama de "claridade labiríntica", construiu espaços interiores intrincados e narrativos, com mudanças bruscas de qualidade, com áreas mais ou menos expostas e cuja escala é variável. Estes espaços devem ser encarados como uma espécie de "pauta" a ser interpretada a cada nova ocupação pelos usuários; como em um happening: o edifício só se completa quando efetivamente ocupado e em constante mutação. Discernimos aqui um impulso de crítica e expansão da área de competência da arquitetura análogo àquele presente na trajetória de alguns artistas.

2 ARANTES, O. G.R. O lugar da Arquitetura depois dos Modernos, 2ª ed., São Paulo, EDUSP, 1995. 


\section{Horizontes e limites da neovanguarda.}

Comparando as produções da arte e da arquitetura percebemos na heterogeneidade das propostas certa unidade de intenções. Assim, a aparente disparidade se torna convergência, delineando a proposta de uma arte e uma arquitetura de intervenção, modificadora do "comportamento" do público e decidida a recuperar o caráter de "obra" da produção material. Se olharmos sob o prisma dos objetivos, a produção neovanguardista apresenta-se como uma inflexão do Movimento Moderno e do modernismo: apesar de suas diferenças, ela manteve-se fiel aos objetivos universalizantes daqueles. Mas constataremos uma mudança profunda se a olharmos a partir das táticas empregadas que se caracterizam pelo abandono do "ponto de vista abstrato e totalizador" moderno, e sua conseqüente reorientação das práticas "rumo ao concreto". O vínculo entre as artes e a arquitetura sedimentou-se como resposta a aspectos sentidos como restrição e imposição, materializados no Movimento Moderno ou por um modernismo crescentemente aceito e ortodoxo. Acreditamos poder, portanto, atribuir um sentido a elas como parte da "rebelião antifordista", ou seja, um aumento "de exigências apresentadas a um estado social que a desaceleração do crescimento econômico começaram a desacreditar" combinado com um inaudito desafio às "virtudes burguesas clássicas da produtividade e da performance individual máxima", desprezadas em favor de uma agenda de "valores pós-aquisitivos", tais como "realização pessoal, solidariedade". ${ }^{3} \mathrm{Na}$ verdade uma "rebelião antifordista" só ganharia sentido em uma sociedade já permeada pelas regulamentações da engenharia social. Contrapõe a estes "obras" porosas às solicitações do cotidiano, solidamente implantadas em seu entorno imediato. A criação da cidade e a experiência da vida deveriam ser confiscadas da mão dos "especialistas" para, abrindo-se ao diálogo, recuperar a dimensão de esfera pública. Por mais contraditórias, as propostas neovanguardistas sempre objetivaram ampliar o elemento de universalidade pressuposto no modernismo. Ou seja, tratava-se de crítica que apontava as limitações existentes no Estado de Bem-Estar e que queria problematizar a Doxa moderna visando tornala mais abrangente, realmente universal. Ao aprofundarmos nossa indagação, constataremos uma situação ambígua: mesmo a reação "antifordista" mais virulenta estava impregnada da lógica da "sociedade administrada". Procuremos enxergar, com os olhos de hoje, os experimentos de ontem: Kaprow definiu a "expansão" como o princípio formal do bappenning, cuja "composição (...) procede exatamente como na assemblage e nos ambientes, ou seja, se desenvolve como uma

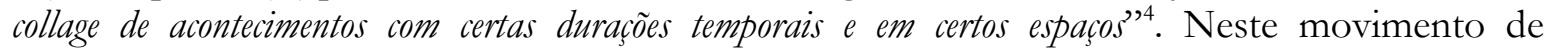
"expansão", que dissolve os limites dos gêneros artísticos, a forma happening/performance atinge outro patamar, uma vez que a articulação de seus elementos (tomados de qualquer gênero de obra ou produção cultural existente) torna-se absolutamente livre, imprevisível, no sentido de não obedecer nenhuma regra de articulação proveniente dos gêneros artísticos (intermidia). Pelo contrário, a forma performance retira sua força expressiva da tensão entre a preservação da identidade de cada elemento que a compõe e a justaposição, aparentemente frouxa ou arbitrária, que promove entre eles. Uma das características inovadoras da performance foi sua imersão no contexto imediato, interagindo com a contingência e particularidade.

\footnotetext{
3 ARANTES, O., "Uma Estratégia Fatal" in ARANTES, O. G.R, VAINER, C., MARICATO, E. A cidade do pensamento único. Desmanchando consensos, Petrópolis/RJ, Vozes, 2000, p. 42.

${ }^{4}$ MARCHAN, S. Del Arte Objetual al Arte de Concepto. 1960-1974, Madri, Alberto Corazón ed., 1974, p. 238.
} 
Permeável às sugestões do cotidiano e do entorno, a performance só constrói seu sentido a partir desta relação, ou seja, era essencial para a "dissolução" da performance no entorno imediato (no cotidiano) a incorporação do tempo/espaço "real" como matéria expressiva. Proclamando um apagamento total dos limites de seu "campo perceptivo", os defensores da performance argumentam que ela, constituindo um evento "em tempo real" que comparte o mesmo espaço do público. A extrema incorporação do elemento "extra-artístico" ao estético, realizada pela performance, implicou na dispersão da identidade da obra, levando à sua hibridização com outras áreas da cultura e com o cotidiano. Como resultado, ela exibe como nota distintiva a intertextualidade, acompanhada pela interatividade. Estas características foram reforçadas pela quebra, promovida intencionalmente, das fronteiras existentes entre obra e o público, que teve que abandonar de vez a posição de observador para entregar-se ao envolvimento com a obra. Em outras palavras, a obra de arte, convertendo-se em performance e, portanto, "teatralizando-se", visa englobar a ação do antigo espectador em sua produção, como parte ou participante em uma "festa" (em oposição à contemplação ou ao "espetáculo"), demandando-lhe uma atitude de "interatividade". A performance visa a instauração da percepção da obra como "presença absoluta". Indo além do conceito de obra como "representação", exacerbando a autoreferencialidade da obra modernista até o paroxismo e mesclando-a com o ideal de experiência autêntica e imediata, sua atuação objetivava instaurar um "presente absoluto", ao acontecer em um espaço/tempo idêntico ao "real". Sendo "apresentação", ela deseja a instauração de uma representação que negue a si mesma ou, como definiria Derrida, "pura presença como pura diferença". Para entender os limites da proposta emancipatória da performance, que "funciona dentro e fora das estruturas de representação", é esclarecedora a analogia com o teatro. As formas deste, por mais que assumam o caráter de improvisação absoluta, desprovida de texto e no umbral entre a vida e a arte, não escapam da condição de "representação". Embora fosse mais do que simpático à idéia da "presença pura", Derrida conclui seu texto sobre as propostas de Artaud indicando a impossibilidade de uma "apresentação" absoluta, alheia à representação. "Pois pelo mero fato de ser teatro sempre incluirá algo de representação e repetição". A tendência de redirecionamento radical "rumo ao concreto" impregnou as performances de características contraditórias. Nelas realiza-se o paradoxo do "espontâneo esteticizado" pois, diferentemente do ritual ou da festa tradicionais nos quais os participantes compartiam um repertório comum, o happening/performance visava a superação dos "comportamentos", ou seja, previa a participação criativa do público pautada pela "tradição do novo". Esta ambigüidade central da performance trará implicações na cena cultural contemporânea, na qual vínculos "sociais" dissolvem-se paulatinamente em "culturais". Assim, as performances encenam uma sucessão de oxímoros ao criarem representações de espontaneidade, o paradoxo do acaso programado. Em suma, fugindo do comportamento e da vida programada caem na estetização da experiência, na "ritualização do espontâneo", originando uma "vivência" peculiar, não taylorizada e nem estandardizada, mas igualmente "desenhada". Contradições semelhantes ameaçaram o contextualismo arquitetônico, que caiu, no pior dos casos, na armadilha de encenar uma "representação" de vida urbana. Segundo Jean Pierre Jeudi a cidade revitalizada segundo idéias derivadas do contextualismo converteu-se em um "museu ao ar livre", pano de fundo para a teatralização da vida quotidiana. A "mudança

${ }^{5}$ CONNOR, S. op. cit. 
de sinal" que sofreu a pesquisa neovanguardista, ao ser incorporada ao mainstream, fundamenta um dos pontos centrais da análise de F. Jameson, a expansão da lógica da mercadoria para as últimas áreas ainda por ela intocadas que ocorreu a partir dos anos 60. Descrita como a "colonização das áreas não produtivas", ela incorporou o Terceiro Mundo, o inconsciente ou ainda aquilo que Lefebvre chamara de o "cotidiano". Tal ponto de vista é reforçado e complementado pela analise de T. J. Clark sobre modernismo (o "sonho mau") no qual o papel que este desempenharia seria o de "colonizador" de áreas culturais ainda não mapeadas, como uma espécie de vanguarda da "consciência burguesa". É ilustrativo neste ponto, rever a utopia de Superstudio de "uma vida como design". A sensibilidade neovanguardista foi em grande medida formatada pelo consumo, então em expansão inaudita. O “Teatro del Mondo" de Veneza reunia a população em torno a um "evento", de maneira semelhante a um happening de Vostell, compartindo o mesmo desejo de converter a cidade e a arte em territórios de atividades criativas abertas à participação em manifestações que deixavam alegremente de lado a contemplação ou a funcionalidade do Alto Modernismo, objetivando a constituição de um cotidiano como locus para a festa. Mas, essa imagem de Veneza não seria mais voltada para o olhar do turista? Os happenings permitiriam a participação realmente ativa e criativa do público? 